\section{\$28. Measurement of Optical Constants of CVD-diamond for Short-wavelength Far-infrared Region}

Nakayama, K., Tazawa, H., Okajima, S. (Chubu Univ.), Kawahata, K., Tanaka, K., Tokuzawa, T., Ito, Y.

A short-wavelength FIR laser diagnostic system of 40 to $70 \mu \mathrm{m}$ in wavelength is under consideration for large volume and high density plasmas[1]. For the wavelength region,a diamond is an exellent material for windows of a laser and a plasma vessel, and for beam-splitters of multi-channel interferometer, because of high transmission in the region with high strength and high thermal conductivity. However, reliable optical constants to design the optical-components are unknown. Therefore, the optical constants (refractive index, absorption coefficient and transmissivity) of the CVD-diamond etalon for $47.64 \mu \mathrm{m}, 57.1511 \mu \mathrm{m}$ and $70.51163 \mu \mathrm{m}$ in wavelength have been measured precisely by using a system shown in Fig.1[2]. In the measurement, the CVD-diamond etalon of $25 \mathrm{~mm}$ in diameter and $1.023 \pm 0.001 \mathrm{~mm}$ in thickness has been used. Figure 2 shows a typical example of transmission signal as a function of incident angle for the $57.1511 \mu \mathrm{m}$ light. The refractive index is decided from the angle of each peak, and the absorption coefficient is obtained from the transmissivity of the first peak.

Table 1 shows the optical constants $(n, \alpha, T)$ of the CVD-diamond obtained for each wavelength. The constants $(n, \alpha)$ are the same for both s- and ppolarization. The accuracy of refractive index is limited to four figures by that of the etalon thickness. As shown in Fig.2, the experimental results agree with the theoretical ones within $\pm 2 \%$. For a crystal quartz etalon at the same thickness, the maximum transmissivity for the extraordinary ray is estimated to be about $68 \%$. It has been verified that the transmissivity of the CVD-diamond is much higher than that of the crystal quartz for short-wavelength far-infrared region.

\section{References}

[1]S. Okajima et al., Rev. Sci. Instrum. vol. 72, pp. 1094-1097, 2001.

[2]K.Nakayama et.al., Digest of 27th Int. Conf. on IR \& MM Waves (USA), 2002 (to be published).

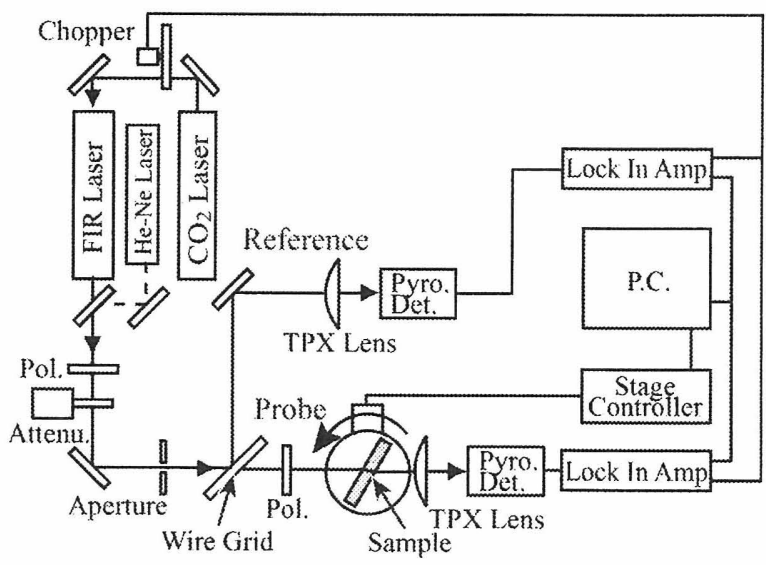

Fig. 1. Block diagram of optical constants measurement system.

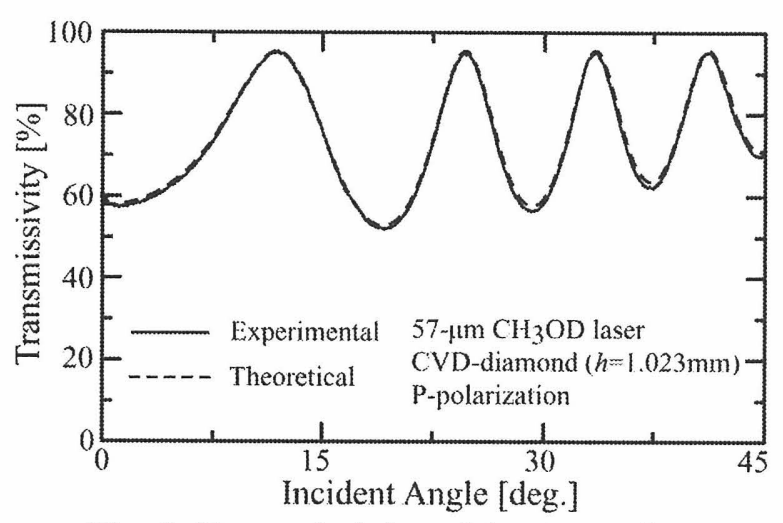

Fig. 2. Transmissivity of the CVD-diamond etalon as a function of the incident angle for $57.1511 \mu \mathrm{m}$ light.

Table 1. Optical constants of CVD-diamond (* at optimum angle for $1.023 \mathrm{~mm}$ in thickness)

\begin{tabular}{c|ccc}
\hline$\lambda[\mu \mathrm{m}]$ & $n$ & $\alpha\left[\mathrm{cm}^{-1}\right]$ & $T[\%]^{*}$ \\
\hline 70.51163 & $2.383(2)$ & 0.19 & $97\left(9.1^{\circ}\right)$ \\
& \pm 0.001 & \pm 0.01 & \pm 1 \\
\hline 57.1511 & $2.383(0)$ & 0.32 & $96\left(11.7^{\circ}\right)$ \\
& \pm 0.001 & \pm 0.02 & \pm 1 \\
\hline 47.65 & $2.382(6)$ & 0.37 & $94\left(10.6^{\circ}\right)$ \\
\hline
\end{tabular}

